\title{
Teachers' virtual communities of practice: A strong response in times of crisis or just another Fad?
}

\author{
Norma Ghamrawi ${ }^{1}$ (D)
}

Received: 29 September 2021 / Accepted: 7 December 2021 / Published online: 23 January 2022 (c) The Author(s), under exclusive licence to Springer Science+Business Media, LLC, part of Springer Nature 2021

\begin{abstract}
The purpose of this study was to investigate the perceived effectiveness of a virtual community of practice (vCoP) designed to support knowledge and expertise sharing between K-12 teachers during Covid-19 pandemic. Besides, it aimed at exploring the potential of such vCoPs in delivering effective professional development, in general, and during crisis in particular. The vCoP was developed by the researcher herself as part of a consultancy to the UNESCO. The sample included 696 participants who were members of the vCoP. The research methodology adopted was mixed methods. Quantitative data was collected through surveying; and qualitative data was collected through 8 focus group interviews each involving 6 participants. Statistical analysis was used to analyze survey data, while interviews data was analyzed using theme-based analysis. Findings showed that participants viewed vCoPs as effective tools for e-professional development in general and during crisis in particular. Facilitators and blockers confronting vCoP nourishment are presented and discussed. Discussions and conclusions are offered at the end of the study.
\end{abstract}

Keywords Virtual communities of practice $\cdot$ Social networking $\cdot$ Professional development $\cdot$ Crisis education $\cdot$ Covid-19 pandemic $\cdot$ Remote education

\section{Introduction}

The Covid-19 pandemic has hit the education sector severely leading to school closure, learning loss and augmented education inequalities even in the case of highest income countries (World Bank, 2021). All reports from international organizations affirm that Covod-19 has amplified marginalization, attrition, disengagement, and stress within the domain of education (Masters et al., 2020; Willis, 2020). According to the UNICEF (2021) children, from across countries, are jeopardized to fall

Norma Ghamrawi

norma.g@qu.edu.qa

1 College of Education, Qatar University, Doha, Qatar 
behind in terms of learning due to school disruptions. As the pandemic continue to prevail, it gets harder to project the size of students' achievement gaps, which seems to be on the rise (Ghamrawi et al., 2020).

While the educational systems across the globe suffer from disorder, turbulence and instability, the safety valve remains to be the teacher (Chase and Taylor-Guy 2020; Schlichter, 2020). A well-prepared and supported teacher is the savior who can play the most crucial and critical role in terms of leveraging the quality and quantity of student learning (UNESCO, 2020a, b). In fact, with the beginning of the pandemic, schools found themselves obliged to switch from one mode to another without any prior preparation (Ghamrawi et al., 2020). Suddenly, the majority of teachers from across the globe were left out with one tool to reach students, mainly technology (NCES, 2019). However, even teachers with advanced IT skills did not feel at ease running online lessons as they lacked the capacity to so (Hollebrands, 2020).

Yet, studies have shown that state and regional endeavors at building the capacity of teachers to handle online or hybrid modes of learning, did not meet the actual needs of teachers (Milman, 2020). Teachers found themselves working in solo, in terms of digitizing their curricula (König et al. 2020). Many webinars run during the pandemic showcased individual teachers' success strategies (Delgado et al., 2021). However, teachers working in isolation are more prone to burnout and mental illness (Dabrowski, 2021). In fact, there is a growing body of research that is highlighting burnout amongst teachers, which researchers are linking to mental sickness due to working in isolation during Covid-19 era (Dabrowski, 2021).

Accordingly, some initiatives were made so as not to leave teachers battling on their own. One of those initiatives was the development of virtual communities of practice for teachers (Bolisani et al., 2020; Delgado et al., 2021; Grunspan et al. 2021). A virtual community of practice ( $\mathrm{vCoP})$ is a platform that "attracts professionals operating in a specific knowledge domain, who share a common problem, interest, or topic" (Bolisani et al., 2020, p.72). Communities of practice (CoPs), whether face-to-face or virtual, are not new in education. However, virtual CoPs have been revitalized during the pandemic, as a response to Covid-19 challenges imposed on teachers (Bolisani et al. 2020).

This study attempted to investigate the effectiveness of one vCoP developed and managed by the researcher herself during her mandate as a consultant to the UNESCO. The focus was on: (a) the features that participant teachers considered to characterize effective virtual communities of practice; (b) the potential of virtual communities of practice in serving as a tool for professional development; and (c) the degree vCoPs may serve as tools to leverage schooling during tumultuous times of crisis.

\section{Context of the study}

Covid-19 pandemic exposed the educational systems around the world, showing their weak resilience and inability to, quickly and efficiently, adapt to change. Interestingly, most of the success stories presented through webinars led by the 
researcher herself all focused on individual teacher initiatives that made differences in the learning and teaching of students. In response to this, the UNESCO seniors thought that the multiple challenges confronting teachers within the Arab states cluster maybe combated through the development of a virtual community of practice that would allow teachers to share their expertise and knowledge. It was hoped that success stories of few teachers would be extrapolated to benefit the wider community of teachers; and not keep them bound to corresponding teachers' classrooms. This was in line with UNESCO's framework of the Agenda for Sustainable Development Goals, leading and coordinating SDG 4 whose aim is to ensure inclusive and equitable quality education and promote lifelong learning opportunities for all. As part of the UNUESCO's 2030 agenda, there is a need to increase the supply of qualified teachers, through international cooperation in terms of teacher training in developing countries. As such, the researcher was selected to serve as a consultant for the UNESCO in order to realize a vCoP devoted for the aforementioned cluster of countries. The aim was to facilitate cross-cooperation between teachers.

The vCop was developed based on an extensive review of the literature of CoPs and vCops alongside the consultant's past experience in developing and leading vCoPs. Figure 1 presents the basis on which the vCoP was developed.

Figure 1 shows that the $\mathrm{vCoP}$ was meant to be: (1) free of any charges so as to encourage the maximum number of teachers from the region; (2) interactive allowing for fast downloads and uploads so as to fit into the weak infrastructure in parts of the targeted region; (3) a manageable space for classified resources and activities; (4) collaborative allowing for sub-communities based on interests and needs; (5) easy in terms of navigation, simulating very popular social media networking Apps, widely used across the globe and the region; (6) well backed up to avoid losses; (7) compatible with social media plug-ins; and (8) accessible through mobile applications (IOS \& Android) accounting for the fact that many users may not have access to laptops or desktops.

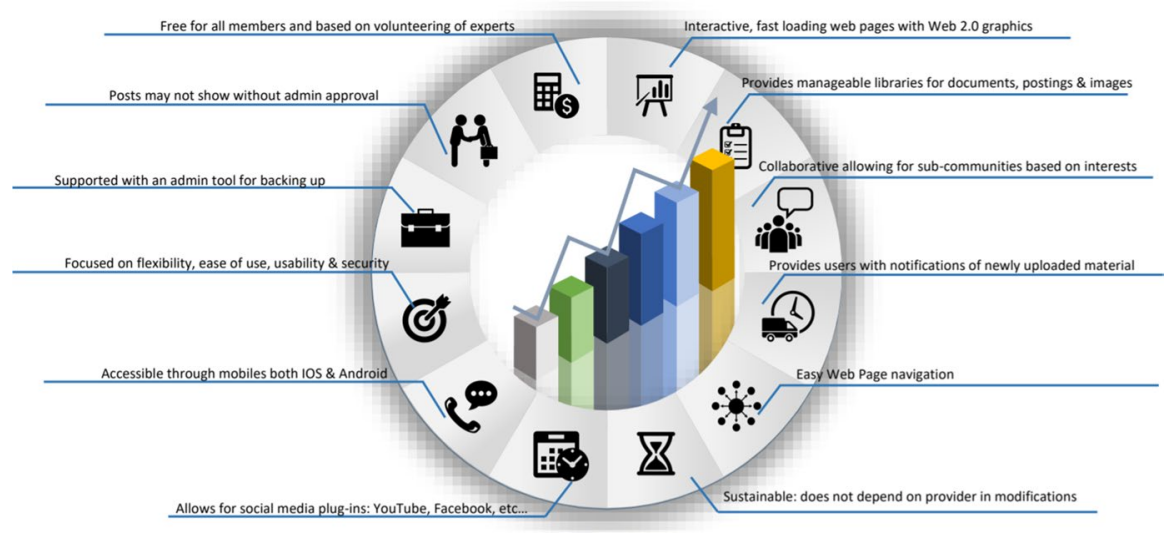

Fig. 1 The pillars on which the vCoP understudy was developed 
The declared mission statement for the vCoP was follows:

\subsection{The virtual community of practice (vCoP) is an online platform for teachers and educators in the Arab region to exchange their expertise with other group members. Its aims to:}

- Enhance networking and collaboration among teachers and educators in the Arab region.

- Serve as a platform allowing for collaborative problem solving and knowledge sharing among teachers and educators

The profile of the vCoP communicated to its community and the public included the following:

- It attracts teachers from the Arab States to share their knowledge and experience.

- It collects teacher-made resources that can be readily get used in teaching.

- It helps teachers get answers to their questions; and get supported with ideas pertaining to the learning $\&$ teaching challenges they get confronted with.

- It secures on-going professional development for teachers.

- It is easily accessible by end users, using Web 2.0 technologies.

- It is accessible through a friendly-user mobile application (IOS \& Android).

- It differentiates services and hence cater for all categories of teachers of various backgrounds.

This study was conducted after the passage of four months since the public launching of the vCoP. During this period, the focus within the vCoP was on supporting teacher members in delivering online lesson, interactively, based on a poll conducted with them. Teachers logged into the vCoP on daily basis several times. Teachers' activity included uploading and downloading resources, initiating discussion boards on problems of interest, contributing to other teachers' discussion boards and attending a weekly webinar. The topics of weekly webinars were chosen after suggestions from the vCop members, followed by polling by all community members.

\section{Importance of the study}

Covid-19 revealed the sad truth that the educational systems across the globe are fragile and that they are unable to absorb shocks confronting them. This is manifested through the international reports such as the UKCISA (2020), U.S. Department of Education (2020), UNESCO (2020a, b), UNICEF (2021) and the World Bank (2021). It is now evident that twenty-first century schooling demands a whole new set of tools, procedures and approaches. Digital literacy and technological infrastructures have proven to be saviors within this crisis, as demonstrated by 
schools and universities that partially managed to meet the challenges (Ghamrawi et al., 2020). Yet the aforementioned reports emphasize the low capacity of schools in general and teachers, in particular to lead on online learning.

This study attempted to investigate the degree a community of teachers from the Arab states region would benefit one another through knowledge and exchange of experiences, to run online learning during the Covid-19 pandemic; via a user-friendly digital platform that is free of charge.

Thus, this study aimed to explore the potential of a vCoP in responding to the professional needs of teachers during times of crisis and to elicit empirical data on the factors that render vCoPs effective platforms for knowledge and expertise exchange. The importance of this study lies in the fact that it derived empirical data from teachers in the battle and while battling. This is a rare opportunity for data collection. Another importance for the study at hand is that it is addressing K-12 teachers. Most studies have addressed vCoPs in higher education settings.

\section{Defining virtual communities of practice}

A community of practice $(\mathrm{CoP})$ stands for a group of individuals interested in a common practice (teaching, business, medicine, engineering, etc..), thus rendering them a community. A virtual community of practice entails those members of the group to meet virtually and not face-to-face through an online platform. In this line, several definitions for vCoPs appear in the literature. Wenger et al. (2002) give the following description for a:

A community of practice is not just a Web site, a database, or a collection of best practices. It is a group of people who interact, learn together, build relationships, and in the process develop a sense of belonging and mutual commitment. Having others who share your overall view of the domain and yet bring their individual perspectives on any given problem creates a social learning system that goes beyond the sum of its parts (p. 34).

Therefore, according to this definition, shared expertise, interests and passion constitute the cement that brings participants together and render them as an independent society.

Likewise, Kirschner and Lai (2007) define vCoPs as being processes rather than a 'thing' conducive for social learning and justify their point by saying:

A community of practice is not really a thing, but rather a process in which social learning occurs because the people who participate in this process have a common interest in some subject or problem and are willing to collaborate with others having this same interest over an extended period. The product of this process is the sharing of ideas, the finding of solutions to common problems and the building of a repository (in the participants and in the group) of available and new knowledge and expertise (p. 28) 
In other words, it can be stated that vCoPs are often characterized by a population who belong to a bubble of shared interest, and who look forward to learn from one another through social interactions.

\section{Knowledge sharing on virtual communities of practice}

Virtual communities of practice are based on knowledge sharing (Harvey et al., 2013). They serve as knowledge ecosystems, where information is shared and generated via social networking around common interests and experience (Shal et al., 2018a, 2018b). The primary motivation for taking part in such communities is the desire to both help and get help from other professionals in the same field (McLaughlan, 2021). A recent systematic review of 42 published studies about virtual communities of practice conducted by Roberto et al. (2021) using PRISMA model (Moher et al., 2009) has arrived at a set of factors that encourage members of a vCoP to share knowledge and expertise. Findings have emphasized four main aspects including; personal, interpersonal, contextual and technological factors.

\section{Personal factors}

Findings from Roberto et al. (2021) pertaining to personal factors, encouraging knowledge sharing on vCoPs are presented in Fig. 2.

Figure 2 shows that some personal motives are behind joining and collaborating on a vCoP. Firstly, helping behaviors or the altruistic prosocial behaviors come on top of those personal attributes. These behaviors entail a thrust within individuals to voluntarily support others. In vCops, these helping behaviors take the shape of knowledge and expertise sharing. Secondly, the need for an affiliation through which membership is pursued for the purpose of leveraging reputation, increasing contacts and growing exposure. Thirdly, getting labeled as an expert is a catalyst for getting involved in vCoPs. Individuals are often encouraged to share knowledge and provide professional sharing based on their experience which they like to be known for. Fourthly, people who prefer self-directed learning are more likely to share knowledge on vCoPs. This is because vCoPs secures for them the mode of

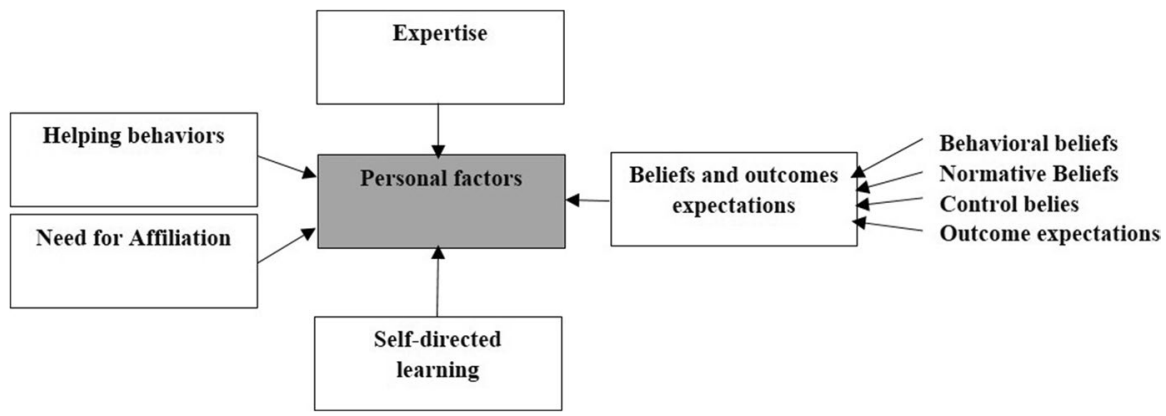

Fig. 2 Personal Factors Underlying Participating in a vCoP (source: Roberto et al., 2021) 
learning they preferred most. Finally, beliefs and outcome expectations can take four forms: (1) behavioral beliefs which relates to reciprocal relationships that supports personal efficacy; (2) normative beliefs in which individuals participate and share under social pressure; (3) control beliefs which is based on personal self-efficacy taking into account both internal and external constraints; and (4) outcome expectations or the feeling that participation will reward them with benefits by the end.

\section{Interpersonal factors}

According to Roberto et al. (2021) the interpersonal factors that impact knowledge sharing by members of a vCoP are presented in Fig. 3.

Figure 3 suggests that trust and justice are integral for the participation of members in knowledge sharing. Members need to feel trusted and to trust others for them to open up. Moreover, vCoP members need to feel that justice prevails within the community, otherwise, they refrain from any sort of collaboration. Leadership is another critical factor, as it ensures effective communication, a clear vision and organization. A third factor is the social ties, which if established among vCoP members, would influence their participation very positively. A fourth factor is expert status, which relates to status and acknowledgement that the vCoP would offer to members. A fifth factor is empowerment, or the tendency of the cVoP to secure opportunities for members to display their knowledge and experience. Finally, the relational structure of the $\mathrm{vCoP}$ is a detriment factor on the long run, as it ensures a proper evolution of interactivity and connectivity amongst members.

\section{Contextual factors}

According to Roberto et al. (2021), the contextual factors that impact knowledge sharing by members of a vCoP has three dimensions as presented in Fig. 4.

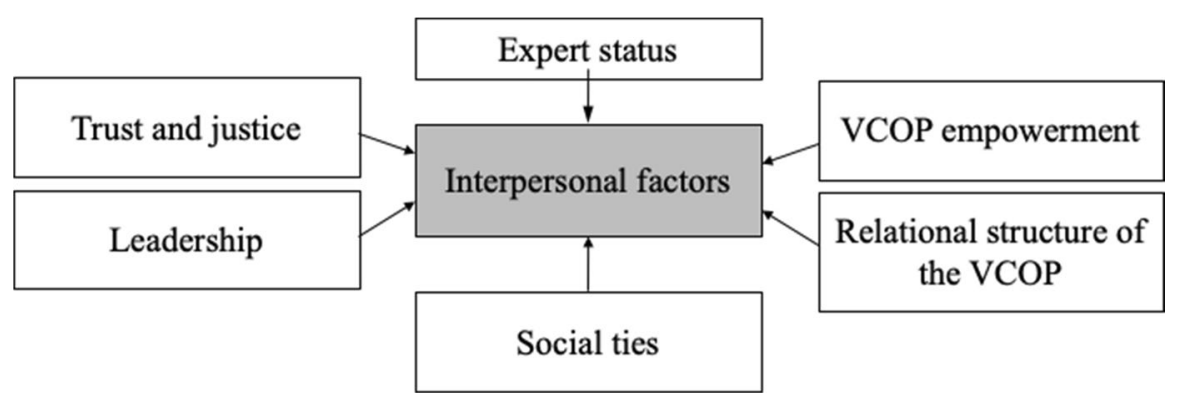

Fig. 3 Interpersonal Factors Underlying Participating in a vCoP (source: Roberto et al., 2021) 


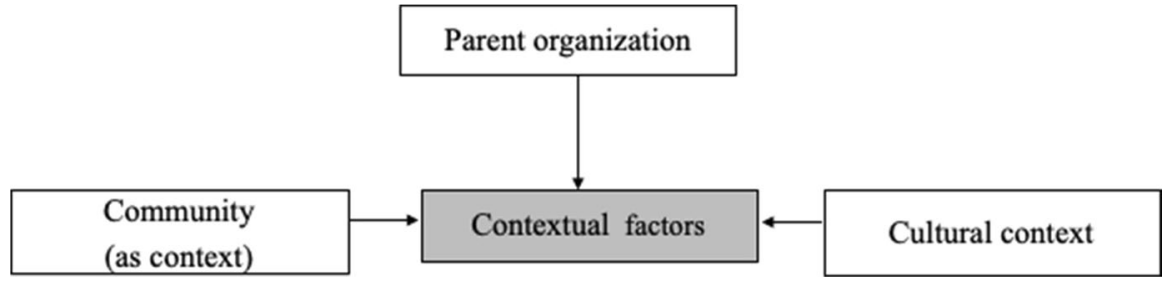

Fig. 4 Contextual Factors Underlying Participating in a vCoP (source: Roberto et al., 2021)

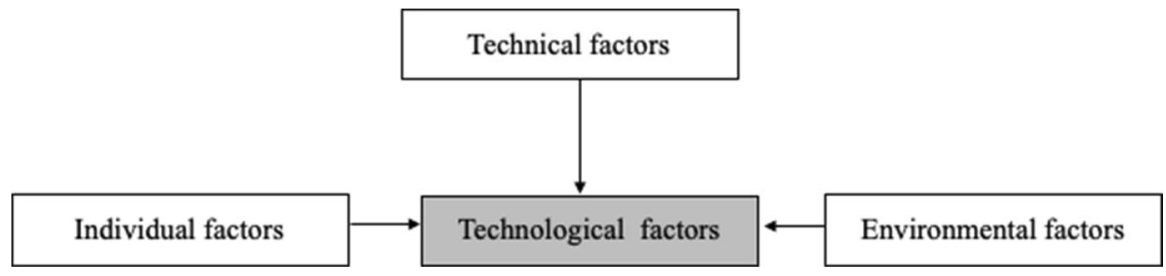

Fig. 5 Technological Factors Underlying Participating in a vCoP (source: Roberto et al., 2021)

According to Fig. 5, a closer match between the community and the daily-work of a member is key for him/her to stick to it. The parent organization, which entails effective organizational culture and support, is a drive for sustained knowledge sharing by the member. Finally, the cultural context that ensures openness, collectivism, competitiveness and credibility is a strong motive for participation within the vCoP.

\section{Technological factors}

Technological factors of three types are recognized as critical factors for sustained vCoP participation as per Roberto et al. (2021), as presented in Fig. 5.

As illustrated in Fig. 5, technological factors include individual factors that relate to the degree a member suffers from technological anxiety. Members who are phobic against technology are less inclined to sustain on a given vCoP. Another factor is the technical factor, which has to do with the platform adopted by the $\mathrm{vCoP}$ and the degree it is user friendly. The more complicated the platforms, the more participants refrain from using and collaborating with others on them. Finally, the environmental factors relate to the quality of the technical support that the vCoP administration provides to users.

\section{Virtual communities of practice and professional development}

While some studies have addressed teacher professional growth through communities of practice (Khalid \& Strange, 2016), the literatures on vCops and teacher professional development is very scarce. Given this, few findings and recommendations 
are noted from such literature. First, based on two case studies in Australia, Hanewald (2013) attributed the failure of one vCoP to the technological illiteracy of members and the struggle they faced in dealing with the vCoP platform. She ascribed the success of the other one to a face-to-face component that was offered along the vCoP activities. She concludes that vCoPs are powerful tools for teachers' professional development as they tend to offer them with the professional support network schemes, leading to development opportunities.

Another study conducted by Moodley (2019) in South Africa, utilized a WhatsApp group post a face-to-face training to sustain the training initiative and provided situational support for teachers who were geographically dispersed. As in the case of Hanewald (2013), Moodley (2019) linked the success of the vCoP to the face-to-face phase and the full acquaintance of the members with the WhatsApp. These findings seem to also coincide with those of a study from New Zealand conducted by Keown (2009). Keown(2009) found that "vCoPs can be effective for teachers but only when the classic model of vCoP is adapted to ensure vCoPs are manageable for, and tailored to, the nature of teachers' working lives" (p. 4). Finally, Ekici (2017) converged with these findings in her study within the Turkish context, but concluded that vCoPs may be useful for the professional development of pre-service teachers only and not in-service teachers.

\section{Purpose of the study}

The purpose of the study was to investigate the characteristics of effective virtual communities of practice through the lens of teachers, and their potential in terms of serving as tools for professional development. Finally, the research attempted to examine the degree vCoPs were effective tools for teacher professional development during crisis, as perceived by teachers themselves.

\section{Research questions}

This study was guided by the following research questions:

1. What are the features that characterize effective virtual communities of practice?

2. What is the potential of virtual communities of practice in serving as a tool for professional development?

3. What role can vCoPs play during crisis?

\section{Research methodology}

\subsection{Research design}

This study used mixed methods from both the positivist and interpretive paradigms. Thus, surveying was used to collect quantitative data to gain breadth of information. 
Following surveying, interviewing was used to collect qualitative data, in order to gain deep empathetic understanding of the points of views of participants.

\section{The sample}

The sample was comprised of 696 participants out of 914 which the number of the vCoP at the time of the study. This figure accounts for almost $76 \%$ of the overall population of the $\mathrm{vCoP}$. All members of the $\mathrm{vCoP}$ were sent invitations to take part in the study specifying the purpose of the study, how data will be used, and the anonymity of participants alongside the survey to be completed in case they were interested and willing to take part in it. Within the first week, 487 completed were returned. Upon recalling the email sent to vCoP members, 209 completed questionnaires were returned during the next week.

After that, invitations were went to the $\mathrm{vCoP}$ members who participated in the survey to take part in a follow up focus group interview, bringing together randomly 6 interviewees via Zoom. Participants were grouped into focus group in the order they responded positively regarding taking part in the interviews. So, the first 6 respondents constituted the first cohort, the second 6 constituted the second cohort, and so on. Upon completing the eighth cohort, 2 additional participants expressed interest in taking part in interviews. The researcher thanked them and informed them that the number of desired interviewees has been reached. The reason behind this was the saturation with data that the researcher noted, whereby themes started recurring.

\section{The research instrument}

The systematic review of 42 published studies about virtual communities of practice conducted by Roberto et al. (2021) using PRISMA model (Moher et al., 2009) constituted the core based on which a survey was created. The survey consisted of three parts. The first part requested demographic and background information such as age bracket, current job title, years of experience and country. The second part addressed the four factors arrived at by Roberto et al. (2021) study; mainly personal, interpersonal, contextual and technological factors. The third part constituted of an open-ended question inviting participants to enlist any additional factors/characteristics that they believed was integral for their participation on the vCop, not mentioned in the second part of the questionnaire. The purpose behind this was to include any factors that were not addressed in the systematic review conducted by Roberto et al. (2021).

Data derived from the questionnaire was meant to answer the first research question: What are the features that characterize effective virtual communities of practice? The survey was revised by two referees one with a $\mathrm{PhD}$ and practical experience in educational technology and another bearing a $\mathrm{PhD}$ and international experience teacher training programs. The feedback offered the researcher 
the opportunity to ensure content validity of the study. There were only few items added pertaining to technical difficulties suggested by the referee with the practical expertise.

Another component of the research instrument was a set of 8 focus group interviews, each including 6 participants. The interview questions were the same as the second and third research question underpinning this study: (1) What is the potential of virtual communities of practice in serving as a tool for professional development? (2) What role can vCoPs play during crisis?

\section{Data analysis methods}

Data derived through questionnaires was analyzed statistically using Statistical Package for Social Sciences (SPSS). Descriptive statistics was used to describe and summarize the mass of data collected from vCoP participant teachers. Mean scores, standard deviation, and percentages were collected per each item.

On the other hand, data collected from the focus group interviews was analyzed thematically. The researcher focused on extracting themes and patterns from transcribed interviews with the help of NVivo 12.0, a software from QSR International which supports in the management of qualitative data analysis.

\section{Results}

\subsection{Demographic data}

Table 1 shows that female participants $(65 \%)$ outweighed male participants $(35 \%)$. The highest number of participants $(39 \%)$ belonged to the age bracket [26-35]. Interestingly, except for novice teachers, the percentages of participants who participated in the study were almost equal in terms of years of experience. Finally, the majority of participants were teachers (82\%).

Participants' geographical distribution across Arab States is presented in Fig. 6.

As shown in Fig. 6, participants came from 17 Arab State. The descending order of participants' numbers per country was as follows: Egypt (101), Lebanon (93), UAE (76), Qatar (61), Iraq (59), KSA (44), Morocco (42), Jordan (31), Kuwait (29), Sudan (26), Algeria (23), Tunisia (22), Yemen (22), Syria (20), Bahrain (19), Libya (17) and Oman (11).

\subsection{Research question 1: What are the features that characterize effective virtual communities of practice?}

Survey data were analyzed statistically to respond to this question. Tables 2, 3, 4 and 5 presents responses of participants on all items of Section 2. Participants responded on a 4-point Likert scale: Strongly Agree (SA), Agree (A), Disagree (DA), and 
Table 1 Gender, Age, Job Position and years of Experience of Participants
$\%$

(rounded

figures)

Gender

$\mathrm{s}$ $35 \%$

Female

$65 \%$

Age (Years)

Less than 25

$17 \%$

26-35

$39 \%$

36-45

$29 \%$

46 and above

$15 \%$

Experience (Years)

Less than 4

5-9

$25 \%$

10- 14

$21 \%$

15- 19

20 and above

Job Position (Involced in K-12)

Teacher

Supervisor/Coordinator

Trainer

$5 \%$

Researcher

$2 \%$

University Professor

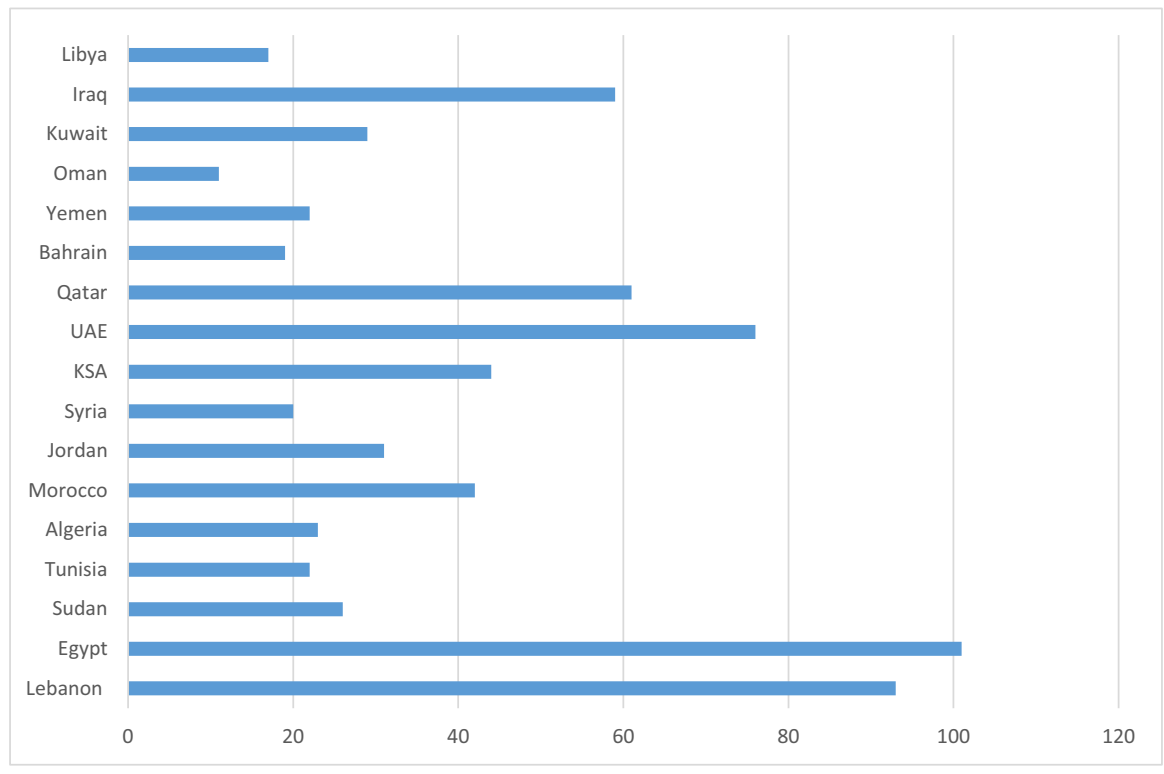

Fig. 6 Geographical Distribution of the Sample 


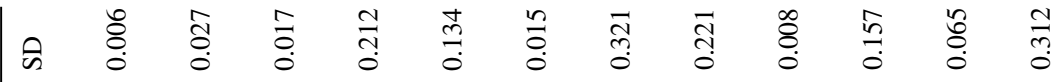

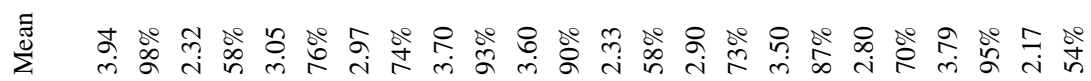

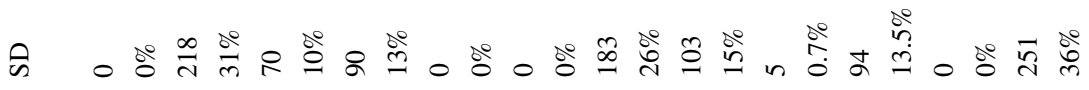

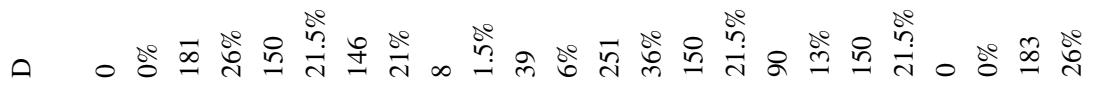
《

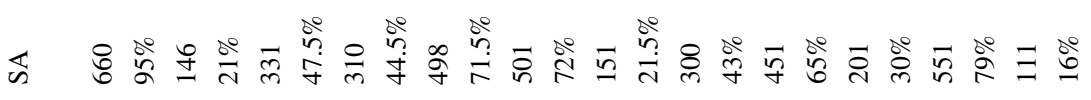<smiles>CCCCC</smiles>

$\Rightarrow \quad \overrightarrow{0}$

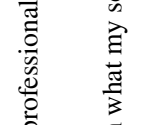

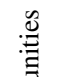

का 壱 产

:

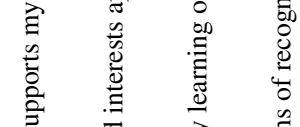

क्षे

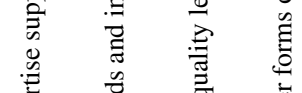

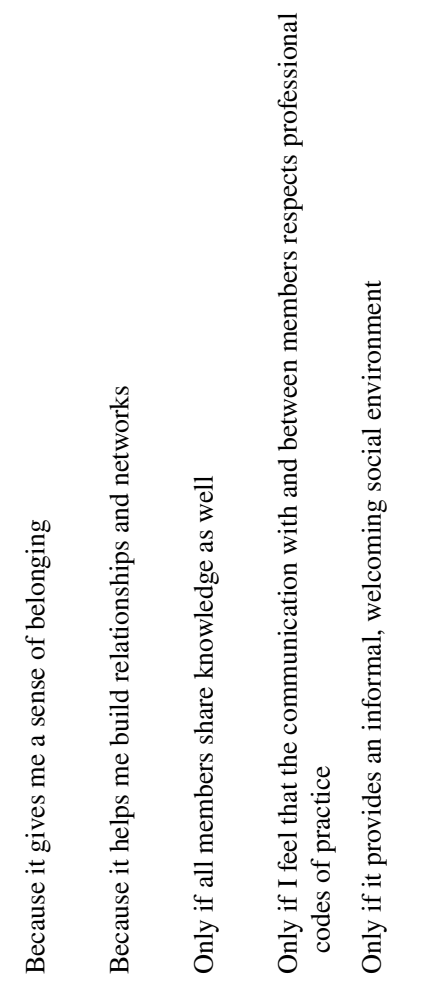




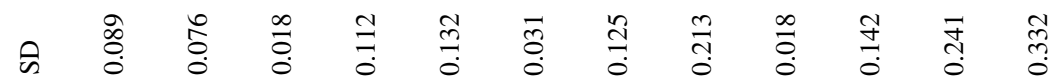

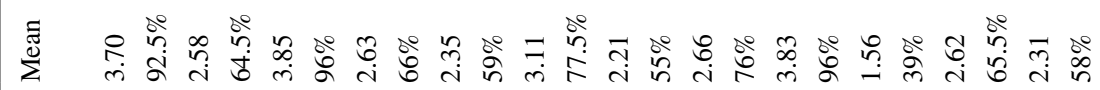

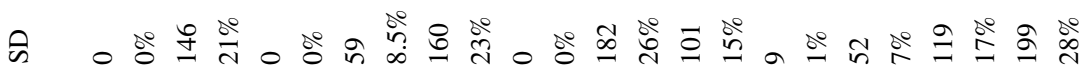

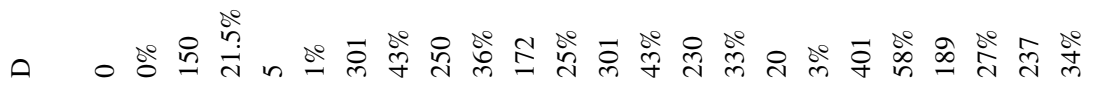

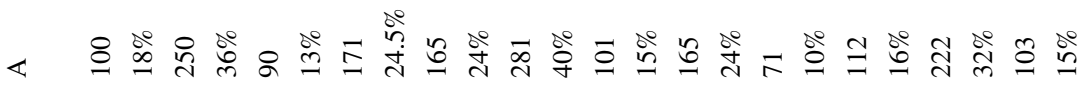

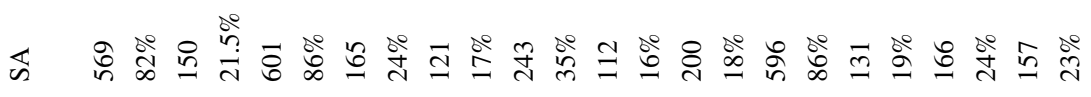

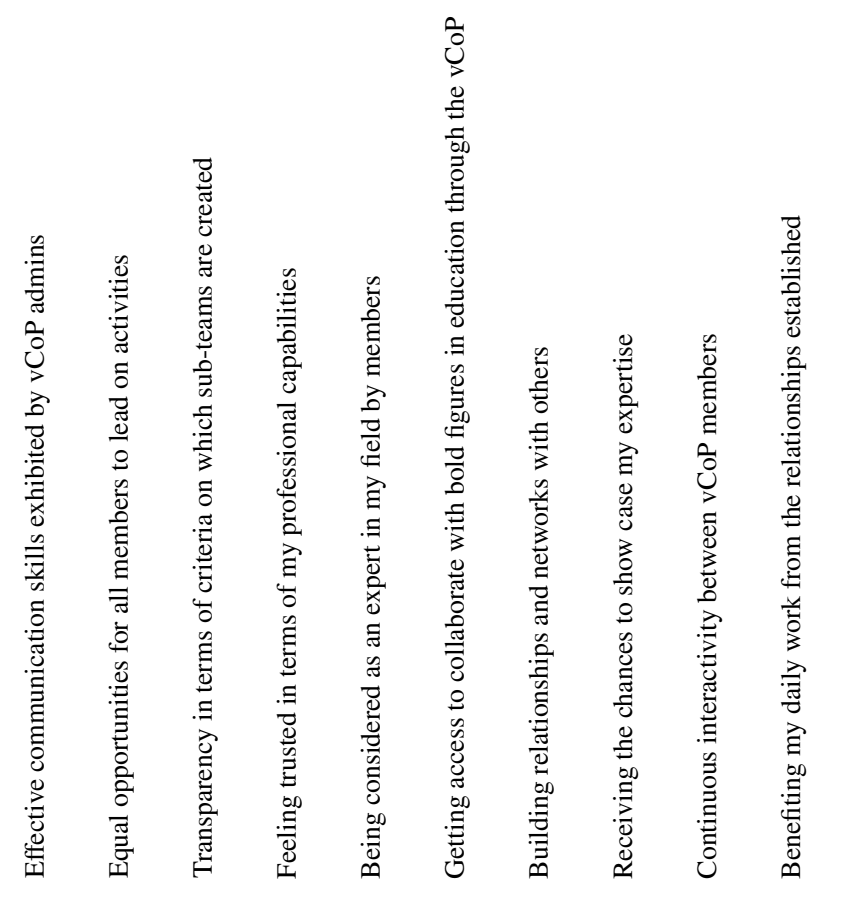




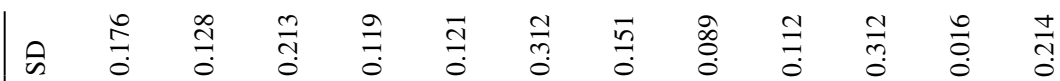

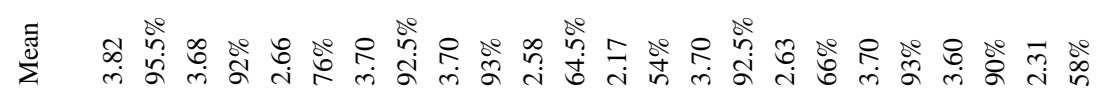

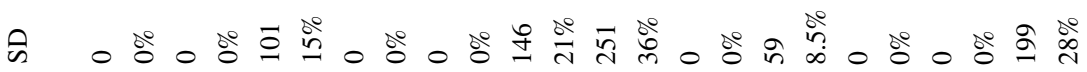

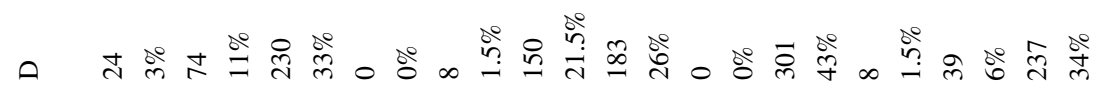

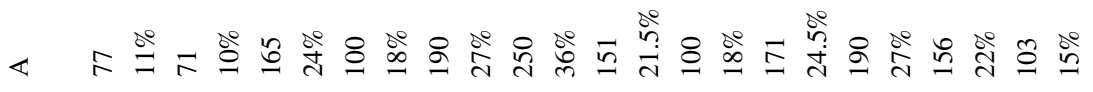

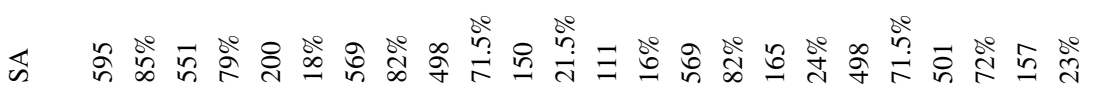
章

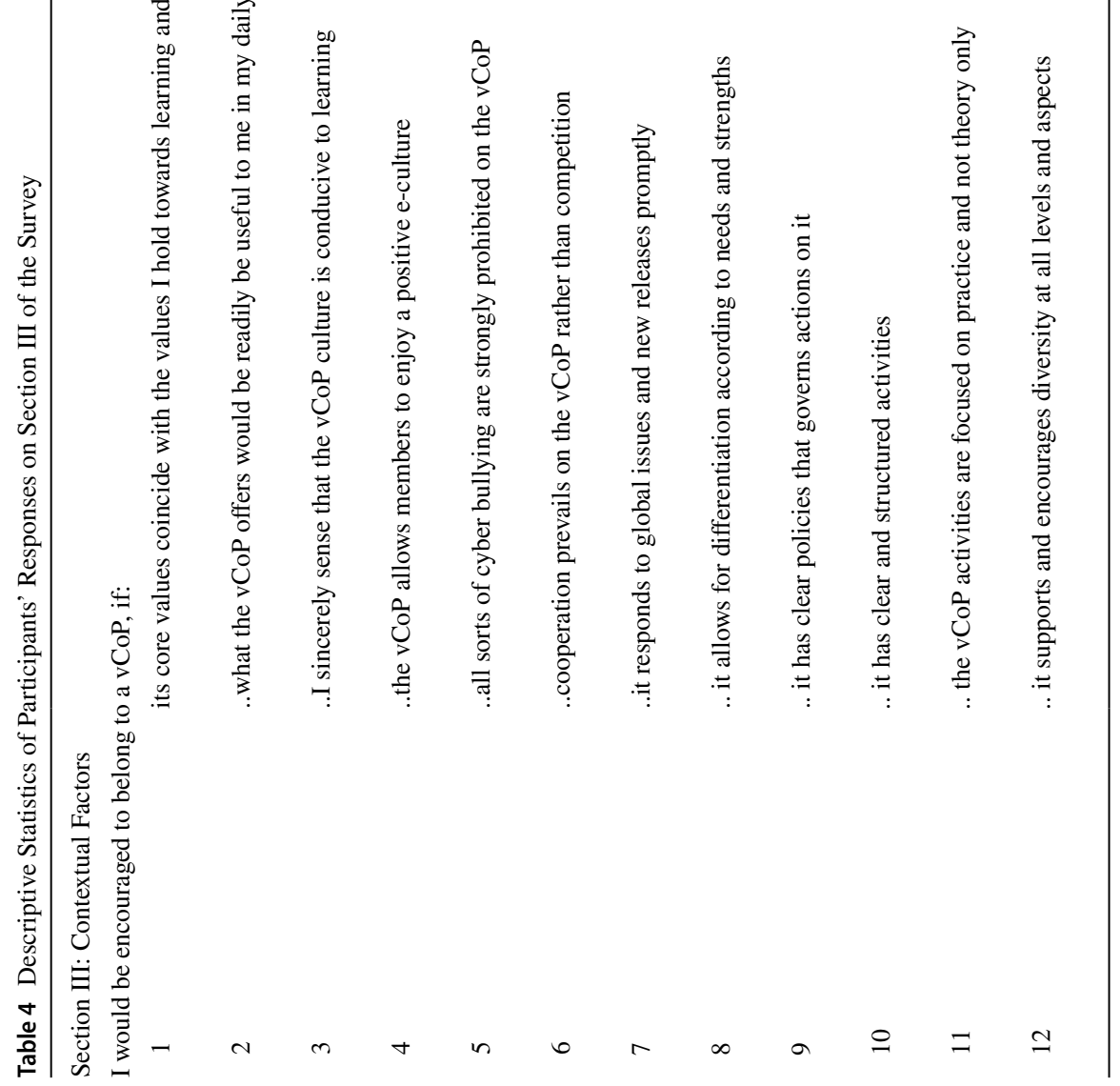




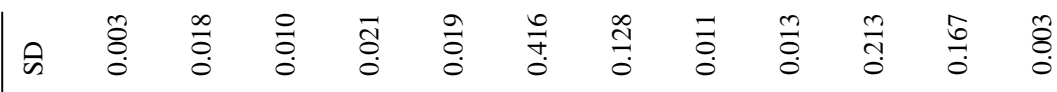

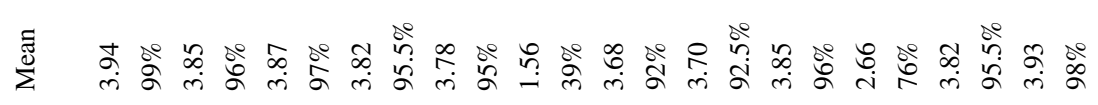

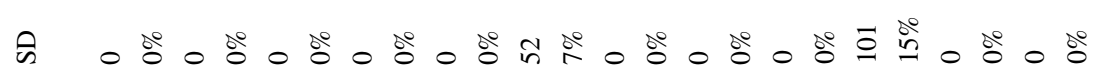

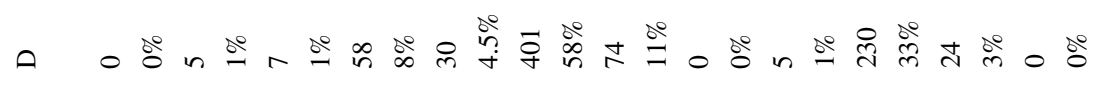

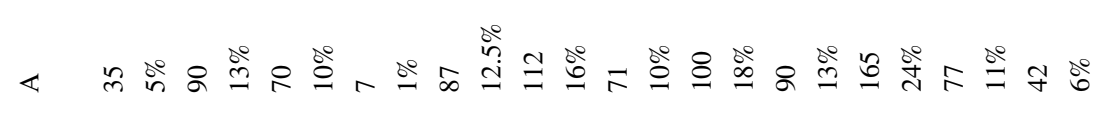

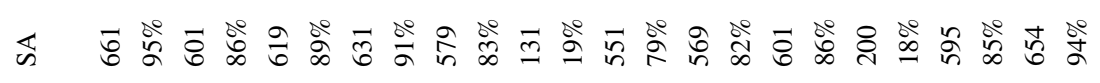


Strongly Disagree (SD). Sections I, II, III, and IV addressed respectively personal factors, interpersonal factors, contextual factors, and technological factors.

Results from Table 2 show that participants rated highest (more than 90\%) three personal factors underlying their willingness to share their knowledge and experience on a vCoP. First, it should match their professional interests (98\%). Second, it should ensure adherence to highest professional codes of respect when it comes to communication. Third, the vCoP should allow members to learn based on their own interests and needs apart from what would be imposed on them by their schools.

Table 3 which focuses on interpersonal factors showed that participants rated highest (more than 90\%) three interpersonal factors constituting strong motives for them to feel encouraged to contribute and collaborate on the vCoP. First, the vCoP should ensure effective communication by its admins. Second, it should allow for networking. Third, a visible and effective leader should lead it, as per participants.

Results from Table 4 show that participants rated highest (more than 90\%) six contextual factors underlying their inclination to belong to a vCoP. First, its core values pertaining to learning and teaching should match the values held by members. Second, it should have well-structured activities. Third, it should secure a positive e-culture. Fourth, it should allow for differentiation. Fifth, its activities and resources should be of the type that would allow members to readily use them in their daily work. Finally, the vCoP activities should be practice-driven as opposed to being theory-driven.

Finally, Table 5 which focuses on technological factors showed that participants rated highest (more than $90 \%$ ) ten technological factors constituting strong reasons for them to remain on the vCoP. These include a user-friendly platform that comes with clear directions on how to use it. It should not require advanced technological skills, and should be easy to register. Additionally, it allow for fast loading of web pages, offer free of charge resources, polls members' opinions around activities it should be offering, and resembles popular social media Apps. Finally, it should allow for easy web navigation, offering technical support at any time.

On the other hand, the third part of the questionnaire invited participants in the study to enlist any other factor that they believed motivated and facilitated their membership on the vCoP, that were not mentioned by the researcher in the second part of the questionnaire. The answers on this part are grouped in a descending order, showing their frequency. It should be noted that some participants mentioned several factors, yet others did not mention any. Additionally, some responses were excluded as the researcher already mentioned them in part (2) of the questionnaire. Responses on the third part of the questionnaire are presented in Table 6.

Table 6 have shown additional factors that vCoP participant members thought would make an added value. While the availability of a mobile App, running weekly webinars and addressing online sessions were already parts of the researched vCoP, virtual exchanges between members, focusing on success stories, catering for teachers who themselves had special needs, as well as student involvement on the vCoP were totally new ideas. 


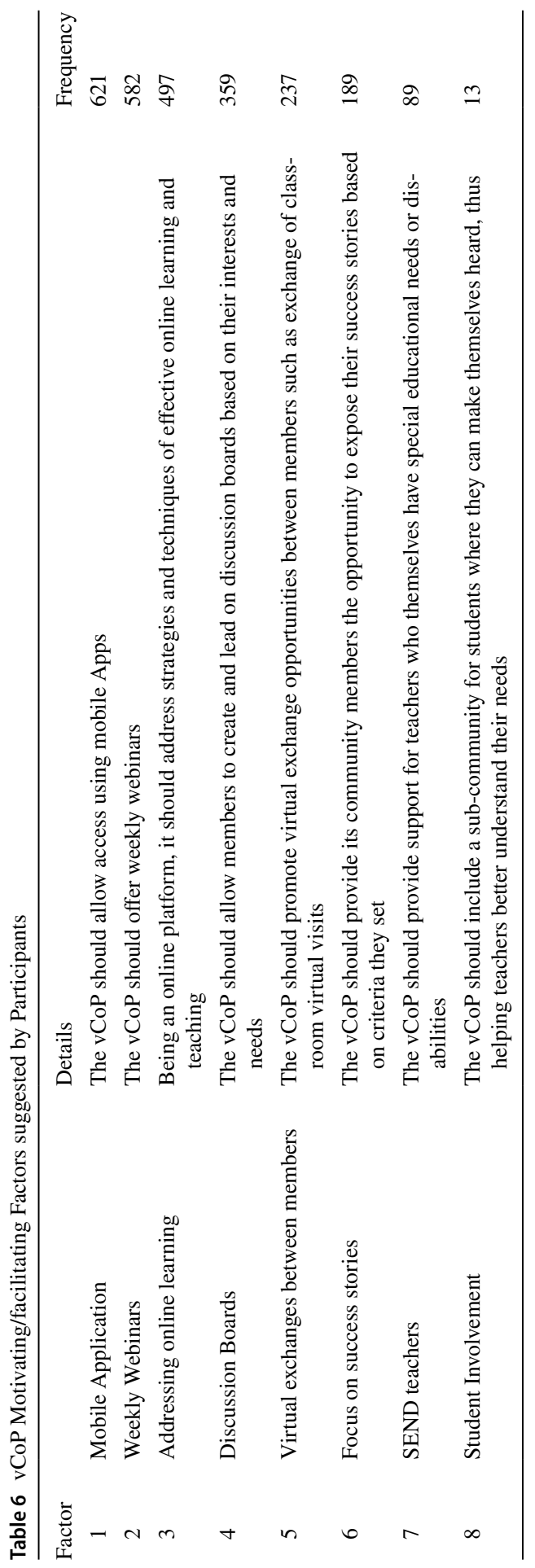




\subsection{Research question 2: What is the potential of virtual communities of practice in serving as a tool for professional development?}

This research question was addressed using data derived through focus group interviews. Interviews data was analyzed thematically with the help of NVivo 12.0. Themes arrived at are presented in Table 7. Participants were given codes in the form of Tx-FGy, where $\mathrm{x}$ is a random number given to a teacher and $\mathrm{y}$ is the number of the focus group given to the interview he/she participated in.

According to Table 7, vCoPs support the professional development by offering differentiated learning opportunities for its members. In other words, it secures personalized learning options allowing for self-directed learning.

"I have never had the chance to choose what really fits my needs and the way I learn as in the case of the vCoP. I feel I am not bound to what is usually imposed collectively on all teachers in the school, without the slightest attention to their preferences and actual needs" (T3- FG6).

"The vCoP allows me to make choices. These choices relate to how, where, when and how much I am interested and in need to learn something. This way I control what I learn and grow accordingly. It makes me learn better because it fits my purpose" (T6-FG2).

"I believe that the vCoP is a tool for differentiating professional growth for teachers the same way we use learning centers in class to differentiate learning for kids. It offers choices and makes you manage your learning. I have never had control over my own learning and growth as during the past three months" (T1- FG8).

Another theme derived from the focus group interviews is that the vCoP secures cost-effective professional development opportunities. In fact, participants in the

Table 7 Themes derived from Focus Group Interviews pertaining to vCoPs serving as tools for professional development (PD)

\begin{tabular}{|c|c|c|}
\hline Themes & & Sub-themes \\
\hline 1 & Differentiated & $\begin{array}{l}\text { - Personalized } \\
\text { - Self-directed }\end{array}$ \\
\hline 2 & Cost-effective & $\begin{array}{l}\text { - Logistics } \\
\text { - Time }\end{array}$ \\
\hline 3 & Globalization & $\begin{array}{l}\text { - Networking } \\
\text { - Borderless exchange }\end{array}$ \\
\hline 4 & Learning Community & $\begin{array}{l}\text { - Learning } \\
\text { - Problem-solving } \\
\text { - Collaboration }\end{array}$ \\
\hline 5 & Teacher Leadership & $\begin{array}{l}\text { - Risk-taking } \\
\text { - Resource expert } \\
\text { - Modelling and coaching }\end{array}$ \\
\hline 6 & Infrastructure & $\begin{array}{l}\text { - Internet connectivity } \\
\text { - Technology devices }\end{array}$ \\
\hline
\end{tabular}


focus group interviews highlighted that because vCoPs are not bound to a place, then training costs are cut down, making PD initiatives less costly.

"When you get trained while being at home or in a coffee shop or in any place you are comfortable to take the training in, then you are cutting down on the costs of using a venue and all that relates to securing coffee breaks for participants, and transportation" (T5- FG4).

"When you adopt vCoPs for training teachers you will pay less on teacher training programs for teachers, because much of the money on training is spent on renting rooms or catering" (T5- FG2).

In addition, interviewed members stressed that training run through the vCoP saves time that is usually spent on transportation to reach training venues. According to teachers, time is the most important asset for a teacher, and the vCoP helps them save it.

"The vCoP has proved to me that professional development can be conducted without making teachers loose much of the time they needed to plan and develop learning materials" (T3- FG6).

"Probably, this [time] is the most precious point behind using vCoPs for teacher training and professional development opportunities. The vCoP saves much of the time we used to spend uselessly (T4- FG5).

The third emergent theme from focus group interviews was globalization. In fact, interviewed members though that the vCoP allowed them to build a strong network with teachers from other countries.

" The vCoP is a strong tool allowing us [teachers] to connect and interact with other teachers in other contexts. It makes us reach out for ideas from expertise at the prick of the finger" (T1- FG6).

" The vCoP has supported me build a real network with teachers from several other countries. It is the first time I really understand the power of networking and how it gets established in practice" (T1- FG8).

Moreover, teachers suggested that the vCoP supported a borderless exchange between themselves.

" Now that I am an active member of the vCoP, I plan lessons with a teacher from the UAE and then develop assessment tools with a teacher from Oman and create resources for my online resources with teacher from Lebanon. It is like travelling from one country to another while you are seated in your arm chair." (T4- FG7).

"I am now on connected to one teachers from an IB school in Qatar and as we both teach the same curriculum and the same grade level; we have started videoconferencing between our students which is highly enriching both of our students" (T2- FG7).

A fourth emergent theme from focus group interviews is establishing a learning community. While this is the concept behind vCoPs, it was recurrent in several of 
the interviews. Participants believed that vCoPs were all about collaborative learning and problem solving pertaining to student learning, thus making members a real learning community.

"All our discussions, posts, webinars, etc... on the vCoP are all about learning: our learning or our students' learning. So, it is really a learning community" (T2-FG1).

"vCoPs are venues for learning. They allow us to learn content pedagogy, teaching strategies, creating remedial programs for our challenged kids, and solving problems related to their learning difficulties very collaboratively. So, they are learning communities in practice.... and to be honest, this is the first time I sense the meaning of a learning community; a term I have always heard of" (T3- FG4).

"The vCoP is a real learning community because it allows us to learn ourselves on one hand, and to discuss problems around student learning. For example, we have learned on the vCoP advanced tools for running online learning. Following that we have collaborated on how to address the problems we encountered while using them" (T3- FG7).

A fifth emergent theme from focus group interviews is teacher leadership. Participant teachers suggested that he vCoP supported them in becoming risk-takers; trying out new stuff, serving as resources experts or serving as coaches for other teachers.

"The vCoP made me move out of my comfort zone. For the first time I felt happy to lead and support other teachers on the platform. I never knew I could do that" (T4-GG1).

"I think the vCoP has highlighted my abilities as an expert in resources. I am the one who is always requested to suggest or share resources on specific concepts in Math" (T1-FG8).

"Well, I am now playing a new role I never had the chance to play in my school. I do not know what to call it but I can describe it: I have been asked by some of the members to attend their online classes and provide them with feedback after I presented a webinar on one learning approach" (T6-FG3).

Finally, teachers warned that all vCoP goals and initiatives might fail in the absence of internet coverage, as well as the needed devices. They assured that mobiles were of good value when laptops were not available, thus stressing the importance of a mobile application to accompany such initiatives.

"I missed many of the things and the benefits other teachers in this interview are mentioning because I did not have internet coverage always" (T5-FG6).

"Other than the internet, devises must be available for participants. Probably the strong aspect of our experience was the availability of a mobile application coming along the vCoP. It made any teacher with a mobile have access to it" (T2-FG7). 


\subsection{Research question 3: What role can vCoPs play during crisis?}

This research question was addressed using data derived from focus group interviews. Interviews data was analyzed thematically, with the help of NVivo 12.0. Themes arrived at are presented in Table 8 .

According to participants and as shown in Table 8, vCoPs have the potential to support teachers' professional development during crisis if they enjoyed 5 key features. The first feature is the availability of the infrastructure that supports the PD activities, including internet and devices. Again, the availability of a mobile application that allows accessing the $\mathrm{vCoP}$ from a mobile was considered an asset.

"Definitely the vCoP is an excellent tool for professional development of teachers during crisis such as Covid-19. But it would fail in the absence of the internet and devices needed to access it........ mobile application is an asset for its success" (T3- FG6).

The second feature of the $\mathrm{vCoP}$ is its high quality content. Participants thought that for a vCoP to be effective during crisis it should respect adult learning modes, offer current resources that should be made available both synchronously and asynchronously, respecting the principles of differentiation.

" The vCoP should continue to respect the fact that learners are teachers and not kids. It should always update its resources, so that anytime it is accessed the member will find new resources " (T4- FG5).

"The vCoP should embed resources that match various needs, paces and levels. These resources should allow access both synchronously and asynchronously" (T2-FG1).

Table 8 Themes derived from Focus Group Interviews pertaining to vCoPs serving as a tool for professional development (PD) during crisis

\begin{tabular}{lll}
\hline Themes & & Sub-themes \\
1 & Infrastructure & $\bullet$ Internet connectivity \\
& & $\bullet$ Technological devices \\
& $\bullet$ Mobile application \\
2 & High Quality Content & - Adult learning protocols \\
& & $\bullet$ Recent and up-to-date \\
& & $\bullet$ Synchronous \& asynchronous \\
& & $\bullet$ Differentiated \\
& & $\bullet$ Existent \\
& & $\bullet$ Leadership \\
& & $\bullet$ Discoussion boards \\
& & $\bullet$ Collective thinking \\
\hline
\end{tabular}


On the other hand, establishing vCoPs by visible leaders before given crisis, has the effect of making it more prune to supporting teacher professional development during such crisis. That was the third theme arrived at through the focus group interviews.

"If this vCoP was established prior to Covid-19 we would have started benefiting starting day-1 of the closure, because it took us sometime to build trust with [you guys] and with members and to even here of it" (T4-FG8).

The fourth feature of a vCoP capable of delivering effective teacher professional development during crisis was its ability to focus on discourse, through discussion boards and collective thinking.

"The power of a vCoP during this crisis [Covid-10] was the discussion boards allowing us to discuss matters of concern. It should also empower member to get along and think together towards a given common challenge or concern" (T6-FG1).

Finally, participants considered responsiveness of a vCoP to the nature of the crisis to be an imperative for its ability to carry out the role of supporting teacher professional development.

"We should keep in mind that the vCoP should react differently according to the nature of the crisis that confronts teachers" (T5-FG3).

\section{Discussion}

The current study explored the effectiveness of a virtual community of practice (vCoP) designed to support knowledge and expertise sharing between K-12 teachers during Covid-19 pandemic. Besides, it aimed at exploring the potential of such vCoPs in delivering effective professional development in general, and during crisis in particular.

The vCoP was assessed using the findings from a systematic review of 42 published studies about virtual communities of practice, conducted by Roberto et al. (2021) using PRISMA model. Findings showed many agreements with the international literature, some disagreements, as well as suggested some additions.

In fact, parallel to the literature reviewed by Roberto et al. (2021), findings suggest that a vCoP would be considered effective through the lens of teachers according to some personal factors on top of which came professional interests, professional codes of respect, and learning based on interests and needs. Opposite to the literature, findings from this study do not suggest that teachers are inclined to take part in vCoPs out of their inclination to support other teachers, or for receiving certificates, or only when vCoPs offer informal welcoming social environments.

As far as interpersonal factors are concerned, this study suggested that ongoing communication, opportunities for networking, and a visible and effective leader of the vCoP are key interpersonal factors that encourage teachers' knowledge sharing on the platform. This comes in line with Roberto et al. (2021) review of literature. 
However, this study seemed to disagree with some features such as making benefit out of the relationships established on the $\mathrm{vCoP}$, receiving the chance to show case one's expertise on the vCoP, or being considered by members as an expert in the field.

At the level of the contextual factors, findings from this study are in agreement with many aspects suggested in the international literature reviewed by Roberto et al. (2021). In fact, this study suggests that the core values of learning and teaching of the vCoP should match those of its members. It should have well-structured activities, secure a positive e-culture, allow for differentiation, provide resources that can be readily used, and that all vCoP activities should refrain from being theoretical. Divergent findings include its responsiveness to global issues, and encouraging diversity at all levels. On an opposite direction to Roberto et al. (2021) this study emphasizes the potential of the $\mathrm{vCoP}$ to allow uploading resources as one essential element for its success.

On the other hand, this study suggests additions to the international literature reviewed by Roberto et al. (2021) including: availability of a mobile App to support the vCoP, running weekly webinars support virtual exchanges between members, focusing on success stories, catering for teachers who themselves have special needs, as well as student involvement on the vCoP.

Finally, findings from this study suggest that vCoPs are strong tools for teacher professional development in general, and in the times of crisis, in particular. The six conditions for a vCoP to serve as a PD platform under normal conditions are presented in the inner part of Fig. 7. The conditions for its effectiveness during crisis are presented along the two curved lines in the same figure. The infrastructure is the feature that is common to both.

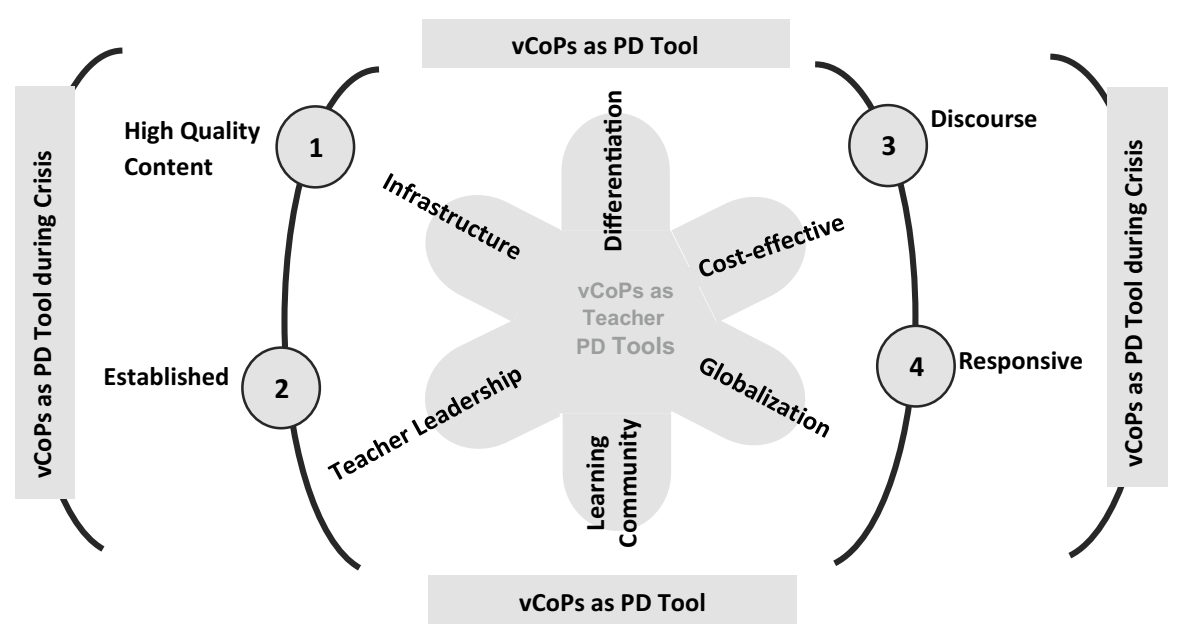

Fig. 7 Factors rendering vCoPs Useful for Teacher Professional Development 


\section{Conclusion}

Findings from this study suggest that vCoPs are powerful tools for professional development of teachers in general, and during crisis in particular. The literature that described the challenges confronting schooling before Covid-19 was already massive. The current pandemic has unveiled the inability of our educational systems to absorb the shocks easily, as it has shown that it lacked resilience. vCoPs are not new in education, as exemplified through the rich literature review offered by Roberto et al. (2021). However, they have received spotlight when they became $\mathrm{t}$ only means for authentic teacher collaboration, collective intelligence and cooperative problem solving. This study suggests that these communities can serve as real saviors in times of crisis, such as Covid-19 pandemic. What makes these communities promising is their flexibility and adaptability. They can be enriching to schools, if well thought of, and effectively planned; so that any time schools are disrupted, they could immediately fill in the gap for teacher PD. VCoPs provide learning and growth by teachers for teachers, thus promoting teacher leadership. Finally, it is of great importance to maintain and sustain such virtual communities of practice post the pandemic era, so that they would be in service and in full function, any time a crisis is in effect.

\subsection{Disclosure of potential conflicts of interest}

There is no potential conflict of interest.

\section{Declarations}

Informed consent All participants in this study were informed of the purpose of the study and how data will be used. They were assured that their identities would remain anonymous across the study.

\section{References}

Bolisani, E., Fedeli, M., De Marchi, V., \& Bierema, L., 2020. Together we win: Communities of Practice to Face the COVID Crisis in Higher Education. In Proceedings of the 17th International Conference on Intellectual Capital, Knowledge Management \& Organisational Learning ICICKM (pp. 72-80).

Chase, A. M., \& Taylor-Guy, P., 2020. Ensuring Continuity of Learning in a Time of Pandemic. AECR news. https://www.acer.org/au/discover/article/ensuring-continuity-of-learning-in-a-time-of-pande mic. Accessed 11 July 2021

Dabrowski, A., 2021. Teacher Wellbeing During a Pandemic: Surviving or Thriving?. Social Education Research, 35-40.

Delgado, J., Siow, S., de Groot, J., McLane, B., \& Hedlin, M. (2021). Towards collective moral resilience: The potential of communities of practice during the COVID-19 pandemic and beyond. Journal of Medical Ethics, 47(6), 374-382.

Ekici, D. I. (2017). The effects of online communities of practice on pre-service teachers' critical thinking dispositions. Eurasia Journal of Mathematics, Science and Technology Education, 13(7), 3801-3827. 
Ghamrawi, N., Shal, T., Machmouchi, I., \& Ghamrawi, N. (2020). Education Inequality Revisited Through the Lived Experiences of Parents During Virtual Learning. Advances in Social Sciences Research Journal, 7(11), 416-433.

Grunspan, D. Z., Holt, E. A., \& Keenan, S. M., 2021. Instructional Communities of Practice during COVID-19: Social Networks and Their Implications for Resilience. Journal of microbiology \& biology education, 22(1), ev22i1-2505.

Hanewald, R., 2013. Teachers' Learning in Online Communities of Practice: Two Case Studies from Australia. International Association for the Development of the Information Society.

Harvey, J.-F., Cohendet, P., Simon, L., \& Dubois, L.-E. (2013). Another cog in the machine: Designing communities of practice in professional bureaucracies. European Management Journal, 31(1), 27-40. https://doi.org/10.1016/j.emj.2012.07.008

Hollebrands, K., 2020. How can Teachers Use Technology in the Classroom: Ask the Expert Series. https://ced.ncsu/news. Accessed 21 July 2021

Keown, P. A., 2009. A virtual community of practice approach to teacher professional development and learning (Doctoral dissertation, The University of Waikato).

Khalid, M. S., \& Strange, M. H., 2016. School teacher professional development in online communities of practice: A systematic literature review. In Proceedings of the 15th European Conference on e-Learning (pp. 605-614). Academic Conferences and Publishing International.

Kirschner, P. A., \& Lai, K. W. (2007). Online communities of practice in education. Technology, Pedagogy and Education, 16(2), 127-131.

König, J., Jäger-Biela, D. J., \& Glutsch, N. (2020). Adapting to online teaching during COVID-19 school closure: Teacher education and teacher competence effects among early career teachers in Germany. European Journal of Teacher Education, 43(4), 608-622.

Masters, G. N., Taylor-Guy, P., Fraillon, J., \& Chase, A. M., 2020. Ministerial Briefing Paper on Evidence of the Likely Impact on Educational Outcomes of Vulnerable Children Learning at Home during COVID-19. https://www.dese.gov.au/system/files/doc/other/ministerial_briefing_paper_ covid19_and_vulnerable_children_acer_22april2020.pdf. Accessed 24 July 2021

McLaughlan, T., 2021. Facilitating factors in cultivating diverse online communities of practice: a case of international teaching assistants during the COVID-19 crisis. The International Journal of Information and Learning Technology. Accessed 29 Aug 2021

Milman, N. B. 2020. Pandemic Pedagogy. https://kappanonline.org/pandemic-pedagogy-covid 19-online-milman/

Moher, D., Liberati, A., Tetzlaff, J., Altman, D. G., The PRISMA Group. (2009). Preferred Reporting Items for Systematic Reviews and Meta-Analyses: The PRISMA Statement. PLoS Medicine, 6(7), e1000097. https://doi.org/10.1371/journal.pmed.1000097

Moodley, M. (2019). WhatsApp: Creating a virtual teacher community for supporting and monitoring after a professional development programme. South African Journal of Education, 39(2), 1-10.

NCES, 2019. Fast Facts: Distance Learning, National Center for Education Statistics, U.S. Department of Education, https://nces.ed.gov/fastfacts/display.asp?id=80 (accessed on 5 May 2020).

Roberto, H. S., Monica, G. O., \& Bartolome, R. A. (2021). Key factors in Knowledge Sharing Behavior in Virtual Communities of Practice: A Systematic Review. Education in the Knowledge Society $(E K S), 22$, e22715-e22715.

Shal, T., El Kibbi, I., Ghamrawi, N., \& Ghamrawi, N. A. R. (2018a). Principalse differentiated learning through social media: Practices and obstacles. International Journal of Education and Applied Research, 8(1), 19-29.

Schlichter, A. (2020). The Impact of Covid-19 on Education: Insights from Education at a Glance. OECD Publishing.

Shal, T., El Kibbi, I., Ghamrawi, N., \& Ghamrawi, N.A.R., 2018b. Web 2.0 - A Tool for learning or socialization only? Perspectives \& experiences of Lebanese school principals. International Journal of Economics and Social Sciences, 8(2), 315-347.

UNESCO, 2020. Half of World's Student Population not Attending School: UNESCO Launches Global Coalition to Accelerate Deployment of Remote Learning Solutions. https://en.unesco.org/news/ half-worlds-studentpopulation-not-attending-school-unesco-launches-global-coalition-accelerate. Accessed 24 July 2021

UNICEF, 2021. Education and COVID-19. Available: https://data.unicef.org/topic/education/covid-19/. Accessed 24 July 2021 
U.S. Department of Education, 2020. CARES Act: Higher Education Emergency Relief Fund, U.S. Department of Education website, https://www2.ed.gov/about/offices/list/ope/caresact.html (accessed on 28 May 2020).

UKCISA, 2020. Coronavirus (Covid-19): Info for international students, UK Council for International Student Affairs website, https://www.ukcisa.org.uk/Information--Advice/Studying--living-in-theUK/Coronavirus-Covid-19-info-forinternational-students (accessed on 12 May 2020).

UNESCO (2020), COVID-19 educational disruption and response, UNESCO website, https://en.unesco. org/covid19/ educationresponse (accessed on 25 Jun 202

Wenger, E., McDermott, R. A., \& Snyder, W. (2002). Cultivating communities of practice. Harvard Business School Press.

Willis, C. (2020). The Impact of Covid-19 on Children's Learning. NFER.

World Bank, 2021. The impact of covid-19 on education - recommendations and opportunities for Ukraine. Available: https://www.worldbank.org/en/news/opinion/2021/04/02/the-impact-of-covid19-on-education-recommendations-and-opportunities-for-ukraine. Accessed 29 Aug 2021

Publisher's note Springer Nature remains neutral with regard to jurisdictional claims in published maps and institutional affiliations.

Norma Ghamrawi , is currently a full professor of educational leadership \& management at the College of Education in Qatar University. She has huge interest in Digital Leadership and its applications in P-12 settings as well as higher education. 